\title{
Thoracoscopic Repair of Congenital Diaphragmatic Hernia in Neonates: Lessons Learned
}

\author{
Anne C. Kim, MD, Benjamin S. Bryner, MS, Begum Akay, MD, James D. Geiger, MD, \\ Ronald B. Hirschl, MD, and George B. Mychaliska, MD
}

\begin{abstract}
Purpose: We sought to characterize our recent experience with thoracoscopic congenital diaphragmatic hernia $(\mathrm{CDH})$ repair and identify patient selection factors.

Methods: We reviewed the medical records of full-term neonatal ( $<1$ month of age) patients who underwent thoracoscopic CDH repair between 2004 and $2008(n=15)$. We obtained data on prenatal diagnosis, characteristics of the $\mathrm{CDH}$ and repair, complications, and outcome.

Results: All patients were stabilized preoperatively and underwent repair at an average of $5.7 \pm 1.3$ days. Six patients were prenatally diagnosed, including the 5 inborn. Thirteen defects were left-sided. All were intubated shortly after birth and 2 required extracorporeal membrane oxygenation (ECMO). Twelve of $15(80 \%)$ patients underwent successful thoracoscopic primary repair, including 1 of the patients who required ECMO prior to repair. Conversion to open repair occurred in 3 of $15(20 \%)$ patients because of the need for patch closure or intraoperative instability. Among those converted to open, all had left-sided CDH defects and 3 had stomach herniation (of 5 such patients). Patients spent an average of $6.9 \pm 1.0$ days on the ventilator following repair. The average time until full-enteral feeding was $16.7 \pm 2.25$ days, and average length of hospital stay was $23.8 \pm 2.73$ days. All patients survived to discharge, and average length of follow-up was $15.3 \pm 3.6$ months.

Conclusions: Thoracoscopic repair of $\mathrm{CDH}$ is a safe, effective strategy in patients who have undergone prior stabilization. Stomach herniation is associated with, but does not categorically predict, conversion to open repair. ECMO use prior to repair should not be an absolute contraindication to thoracoscopic repair.
\end{abstract}

\section{Introduction}

I

NCREASING POPULARITY of minimally invasive surgical (MIS) techniques has led to the use of these techniques for more complex pediatric surgical problems. Repair of congenital diaphragmatic hernia $(\mathrm{CDH})$ is no exception and successful repair by laparoscopic and thoracoscopic techniques were initially reported in infants and children. ${ }^{1-3}$ Our early experience indicated that refinements in technique and better patient selection criteria would be necessary for successful MIS repair of neonatal $\mathrm{CDH}^{4}{ }^{4}$ Subsequently, neonatal thoracoscopic $\mathrm{CDH}$ repair has been successful with primary repairs, ${ }^{5-12}$ as well as with patch repairs. ${ }^{6,13,14}$ Recent efforts have been made to delineate selection criteria predictive of the need for primary versus patch repair, because the latter tends to predict the need for conversion to open repair. We sought to characterize our recent experience with thoracoscopic $\mathrm{CDH}$ repair and examine selection criteria that predicted the need to convert to open repair.

\section{Methods}

After receiving approval from our Institutional Review Board (IRBMED, University of Michigan Medical School protocol approval \#HUM 00025603), we reviewed the medical records of 15 near- and full-term neonatal patients who underwent thoracoscopic CDH repair between 2004 and 2008 . All patients included in this study underwent repair within the first 30 days of life. During the study period, these patients were cared for by a team of seven pediatric surgeons. Patients diagnosed prenatally at our institution received serial ultrasounds with calculation of lung-to-head ratio (LHR) and 
determination of liver position. ${ }^{15}$ Following delivery, all patients were managed by using a gentle ventilation technique to maintain peak inspiratory pressure (PIP) $\leq 25 \mathrm{cmH}_{2} 0$, peak end-expiratory pressure (PEEP) of $5 \mathrm{cmH}_{2} \mathrm{O}$, respiratory rate (RR) less than 70 breaths per minute $(\mathrm{bpm})$, and fraction of inspired oxygen $\left(\mathrm{F}_{\mathrm{i}} \mathrm{O}_{2}\right)$ was weaned to maintain preductal oxygen saturation above $85 \%$, as long as perfusion was adequate. ${ }^{16,17}$ After patients were stabilized from a respiratory and cardiac perspective, they were taken to the operating room for $\mathrm{CDH}$ repair. Patients considered for thoracoscopic repair met the following criteria: 1) preoperative stability with gentle ventilation parameters, 2) no evidence of pulmonary hypertension, and 3) no major associated anomalies.

\section{Operative technique}

Single-lung ventilation was not required. A 5-mm initial trocar was placed below the tip of the scapula or in the midaxillary line at the level of the nipple and insufflation of the thorax undertaken with approximately $4-7 \mathrm{~mm} \mathrm{Hg}$ of pressure. After placement of the thoracoscope, two additional trocars, between 3 and $5 \mathrm{~mm}$, were placed under direct visualization. In two thirds of the patients, the additional instruments were placed under direct visualization through two small stab incisions. Following reduction of the hernia contents into the abdominal cavity and delineation of the edge of the diaphragm, primary repair was undertaken with interrupted 2-0 Ethibond (Ethicon, Inc., Somerville, NJ) or silk sutures tied intracorporeally. If necessary, pledgetted sutures were used in areas of attenuated diaphragm. If the lateral portion of the diaphragm needed reinforcement, this was done with a pericostal suture placed either intracorporeally or by use of a Carter-Thomason needle (Inlet Medical, Inc., Eden Prairie, MN $)^{12}$ under direct visualization with the knot secured within the subcutaneous tissue. Chest tubes were not used routinely, but were used per surgeon preference. If the procedure was converted to open repair, a subcostal incision was made and intra-abdominal reduction of the hernia contents undertaken. When there was an inadequate diaphragm for primary repair, the repair was completed by using a patch of synthetic or biologic material.

\section{Data collection and statistical analysis}

Patient demographic data including estimated gestational age (EGA), birth weight, Apgar scores, inborn/outborn status, associated anomalies, and information on prenatal diagnosis [LHR or magnetic resonance imaging (MRI) lung volume data, if available], were recorded. Indicators of CDH severity were also recorded, such as liver or stomach herniation, ventilator settings, arterial blood gas (ABG) values, and the use of treatment beyond conventional ventilatory management, such as surfactant, high-frequency oscillatory ventilation (HFOV), or extracorporeal membrane oxygenation (ECMO). Operative repair data were noted, including day of life (DOL) at repair, operative time, conversion to an open operation, need for patch repair, and placement of a chest tube. Outcome variables included survival, number of total and postoperative ventilator days, DOL when tolerating full enteral feeding, and length of hospital stay (LOS). In addition, the incidence and type of complications, as well as recurrences, were recorded. Descriptive and $t$-test statistics were performed by using SPSS (SPSS Inc., Chicago, IL) and Excel (Microsoft Corp, Redmond, WA).

\section{Results}

\section{General characteristics and outcomes}

We identified 15 neonatal patients who underwent attempted thoracoscopic $\mathrm{CDH}$ repair. They had an average EGA of $38.6 \pm 0.3$ weeks (range, 35-40). Average birth weight was $3.4 \pm 0.1 \mathrm{~kg}$, and mean Apgar scores at 1 and 5 minutes were $6.2 \pm 0.5$ and $8.1 \pm 0.4$, respectively. All survived; predicted survival by the $\mathrm{CDH}$ Study Group equation was $0.83 \pm 0.03$. $^{18}$ Thirteen defects were left-sided $(87 \%)$, with no liver herniation. The 2 right-sided defects had liver herniation. Prenatal diagnosis was possible in the 5 inborn patients; information regarding prenatal diagnosis was not available in the single outborn patient with a prenatal diagnosis (see Table 1). Prenatal evaluation of patients with $\mathrm{CDH}$ included calculation of LHRs. LHRs were calculated in 4 of the 5 patients and most fell in a very favorable range $(>1.4)$, with a mean of $1.8 \pm 0.2$. The sole cardiac abnormality was a ventricular septal defect. Five patients had stomach herniation, as determined by chest radiograph.

The average DOL at the time of repair was $5.7 \pm 1.3$ days and average weight at the time of repair was $3.5 \pm 0.2 \mathrm{~kg}$. The repairs took an average of $161 \pm 19$ minutes. The number of

\section{Table 1. Patient Characteristics and Outcomes}

\begin{tabular}{|c|c|}
\hline & $\mathrm{n}(\%)$ \\
\hline Survival & $15(100)$ \\
\hline Left-sided & $13(87)$ \\
\hline Male & $10(67)$ \\
\hline Inborn & $5(33)$ \\
\hline Prenatal diagnosis & $6(40)$ \\
\hline Had LHR calculated & $4(27)$ \\
\hline Mean LHR ( \pm SEM) & $1.8 \pm 0.2$ \\
\hline Cardiac abnormalities & $1(7)$ \\
\hline Type & VSD \\
\hline Liver herniation by prenatal ultrasound & $2(14)$ \\
\hline Side of defect & Right $\times 2$ \\
\hline \multirow[t]{2}{*}{ Stomach herniation by radiograph } & $5(29)$ \\
\hline & Mean $\pm S E M$ \\
\hline EGA (weeks) & $38.6 \pm 0.3$ \\
\hline Birth weight $(\mathrm{kg})$ & $3.4 \pm 0.1$ \\
\hline Apgar (1 minutes) & $6.2 \pm 0.5$ \\
\hline Apgar (5 minutes) & $8.1 \pm 0.4$ \\
\hline CDHSG predicted survival & $0.83 \pm 0.03$ \\
\hline \multicolumn{2}{|l|}{ Outcomes } \\
\hline DOL at repair & $5.7 \pm 1.3$ \\
\hline Weight at repair $(\mathrm{kg})$ & $3.5 \pm 0.2$ \\
\hline Duration of repair (minutes) & $161 \pm 19$ \\
\hline Total ventilator days & $12.6 \pm 2.1$ \\
\hline Postoperative ventilator days & $6.9 \pm 1.0$ \\
\hline DOL at full enteral feeding & $16.7 \pm 2.3$ \\
\hline LOS (days) & $23.1 \pm 2.3$ \\
\hline Length of follow-up (months) & $15.3 \pm 3.6$ \\
\hline
\end{tabular}

CDHSG, Congenital Diaphragmatic Hernia Study Group; DOL, day of life; EGA, estimated gestational age; LHR, lung-to-head ratio; LOS, length of stay; SEM, standard error of mean; VSD, ventricular septal defect. 
total and postoperative ventilator days averaged $12.6 \pm 2.1$ and $6.9 \pm 1.0$ days, respectively. Patients were, on average, at DOL 12.6 when extubated and DOL 16.7 when on full enteral feeding. Length of stay was $23.8 \pm 2.3$ days, on average, and length of follow-up was $15.3 \pm 2.3$ months.

\section{Comparison of completely thoracoscopic to repairs converted to open}

When patients repaired thoracoscopically $(\mathrm{T}, n=12)$ were compared to those who required conversion to open repair $(\mathrm{TO}, n=3)$, there were no significant differences in general characteristics, such as birth weight, Apgar scores, and CDHSG predicted survival. Ventilator settings were generally minimal, with no significant differences between the $\mathrm{T}$ and TO groups. Average values were approximately $21 \mathrm{~cm} \mathrm{H}_{2} \mathrm{O}$ for $\mathrm{PIP}, 5 \mathrm{cmH}_{2} \mathrm{O}$ for PEEP, 0.30 for $\mathrm{F}_{\mathrm{i}} \mathrm{O}_{2}$, and $48-52 \mathrm{bpm}$ for respiratory rate (see Table 2). Preoperative ABG data revealed mild hypercapnia but were otherwise unremarkable; there were no significant differences between groups.
Twelve of 15 patients were maintained on conventional ventilation alone. In the T group, 1 patient required a one-time use of surfactant and another required a 4-day course of ECMO. In the TO group, 1 patient required both HFOV and a 2-week course of ECMO. Both patients who required ECMO were successfully weaned off of it and remained hemodynamically stable prior to operative repair. Five patients in the $T$ group received intraoperatively placed chest tubes and 1 for a postoperative pneumothorax; 2 patients in the TO group received intraoperatively placed chest tubes.

One patient in the TO group underwent repair far later than the other patients studied (DOL 23, compared to 5.7, on average), resulting in a higher average DOL at repair for the TO group (11.3 \pm 5.9 days, as opposed to $4.3 \pm 0.4$ for $\mathrm{T})$. Duration of repair was longer with conversion to open repair (155 \pm 23 minutes for $\mathrm{T}, 195 \pm 13$ for $\mathrm{TO})$. Total ventilator days were longer for the TO group (9.7 \pm 0.9 days for $\mathrm{T}, 24.4 \pm 6.8$ for $\mathrm{TO})$, comprised mainly of a significant difference in postoperative ventilator days ( $5.4 \pm 0.7$ days for $\mathrm{T}, 13.1 \pm 1.2$ for TO; $P<0.001)$. The TO group experienced a later DOL when on

Table 2. Comparison of Thoracoscopic Repair to Those with Conversion to Open

\begin{tabular}{|c|c|c|c|}
\hline & $\begin{array}{l}\text { Thoracoscopic }(T)(\mathrm{n}=12) \\
\quad(\text { mean } \pm S E M)\end{array}$ & $\begin{array}{c}\text { Thoracoscopic }->\text { open }(T O)(\mathrm{n}=3) \\
(\text { mean } \pm \text { SEM })\end{array}$ & P-value \\
\hline EGA (weeks) & $38.5 \pm 0.4$ & $38.9 \pm 0.3$ & 0.688 \\
\hline Birth weight $(\mathrm{kg})$ & $3.4 \pm 0.2$ & $3.2 \pm 0.1$ & 0.554 \\
\hline Apgar (1 minutes) & $6.2 \pm 0.6$ & $6.3 \pm 1.2$ & 0.900 \\
\hline Apgar (5 minutes) & $8.3 \pm 0.4$ & $7.3 \pm 1.2$ & 0.324 \\
\hline CDHSG predicted survival & $0.85 \pm 0.02$ & $0.75 \pm 0.10$ & 0.422 \\
\hline PIP $\left(\mathrm{cmH}_{2} 0\right)$ & $21.1 \pm 0.8$ & $21.7 \pm 2.3$ & 0.763 \\
\hline PEEP $\left(\mathrm{cmH}_{2} 0\right)$ & $5.0 \pm 0$ & $5.3 \pm 0.3$ & 0.420 \\
\hline $\mathrm{F}_{\mathrm{i}} \mathrm{O}_{2}$ & $0.30 \pm 0.03$ & $0.32 \pm 0.06$ & 0.739 \\
\hline Rate (bpm) & $48 \pm 3$ & $52 \pm 4$ & 0.671 \\
\hline $\mathrm{pH}$ & $7.368 \pm 0.017$ & $7.363 \pm 0.060$ & 0.925 \\
\hline $\mathrm{pCO}_{2}$ & $47.8 \pm 1.9$ & $48.7 \pm 0.6$ & 0.814 \\
\hline $\mathrm{pO}_{2}$ & $75.2 \pm 6.9$ & $77.9 \pm 10.7$ & 0.856 \\
\hline $\mathrm{HCO}_{3}$ & $27.2 \pm 1.7$ & $27.7 \pm 3.7$ & 0.916 \\
\hline $\mathrm{SaO}_{2}$ & $94.3 \pm 1.3$ & $96.7 \pm 0.9$ & 0.360 \\
\hline DOL at repair & $4.3 \pm 0.4$ & $11.3 \pm 5.9$ & 0.353 \\
\hline Duration of repair (minutes) & $155 \pm 23$ & $195 \pm 13$ & 0.489 \\
\hline Total ventilator days & $9.7 \pm 0.9$ & $24.4 \pm 6.8$ & 0.159 \\
\hline Postoperative ventilator days & $5.4 \pm 0.7$ & $13.1 \pm 1.2$ & $<0.001$ \\
\hline DOL at full enteral feeds & $13.3 \pm 1.1$ & $30.3 \pm 5.8$ & 0.094 \\
\hline \multirow[t]{2}{*}{ LOS (days) } & $19.8 \pm 1.3$ & $36.3 \pm 5.6$ & 0.001 \\
\hline & $n=$ & $n=$ & \\
\hline Stomach herniation by radiograph & 2 & 3 & \\
\hline Required ECMO & 1 & 1 & \\
\hline Time on ECMO (days) & 4 & 14 & \\
\hline Required HFOV & 0 & 1 & \\
\hline Required surfactant & 1 & 0 & \\
\hline Received chest tube ${ }^{a}$ & 6 & 2 & \\
\hline Required patch repair & 0 & 2 & \\
\hline Postoperative complications & 1 & 3 & \\
\hline Pleural effusion & 0 & 1 & \\
\hline Pneumonia & 0 & 1 & \\
\hline Pneumothorax & 1 & 1 & \\
\hline Recurrence & 2 & 0 & \\
\hline Timing (DOL) & 215 , unknown & & \\
\hline
\end{tabular}

ABG, arterial blood gas; bpm, breaths per minute; CDHSG, Congenital Diaphragmatic Hernia Study Group; DOL, day of life; ECMO, extracorporeal membrane oxygenation; EGA, estimated gestational age; $\mathrm{F}_{\mathrm{i}} \mathrm{O}_{2}$, fraction of inspired oxygen; HFOV, high-frequency oscillatory ventilation; LOS, length of stay; PEEP, peak end-expiratory pressure; PIP, peak inspiratory pressure; SEM, standard error of the mean.

${ }^{a}$ All chest tubes placed intraoperatively except one for postoperative pneumothorax in T group. 
full enteral feeding $(13.3 \pm 1.1$ days for $\mathrm{T}, 30.3 \pm 5.8$ for $\mathrm{TO}$; $P=0.094)$ and a significantly longer length of stay $(19.8 \pm 1.3$ days for $\mathrm{T}, 36.3 \pm 5.6$ for $\mathrm{TO} ; P=0.001$ ).

All 3 patients in the TO group had stomach herniation, of 5 such patients. Two patients in the TO group required patch repairs, while no patients in the $\mathrm{T}$ group required one. The need for a patch was the indication for conversion to an open repair in 2 of the 3 patients, with 1 patch repair initially attempted thoracoscopically. The other patch repair was immediately converted to open due to the limited amount of native diaphragm present. The other patient in the TO group experienced prohibitively high intraoperative PIP levels, prompting a conversion to an open repair. There were a total of $4(27 \%)$ complications, 3 of which occurred in the T group. Complications included pneumothoraces in 2 patients, and a pleural effusion and case of pneumonia in 2 other patients. Two cases of recurrence were noted in the T group, 1 at DOL 215 and the other at an unknown time (the patient was treated at another institution).

\section{Discussion}

Thoracoscopic $\mathrm{CDH}$ repair is a safe, effective operative approach in neonates. Surrogate markers for the severity of a diaphragmatic defect, such as LHR or the predicted survival estimated by the CDHSG equation, suggest that less severe $\mathrm{CDH}$ can be successfully treated with thoracoscopic repair. While stomach herniation was associated with a need for conversion to an open repair, it did not necessarily exclude thoracoscopic repair. Preoperative need for ECMO should not necessarily be considered a contraindication to thoracoscopic repair, if the patient demonstrates subsequent stability.

Minimally invasive operative techniques are being explored with increasing enthusiasm in pediatric surgery. Among the benefits of these techniques are decreased postoperative pain and improved long-term cosmesis. CDH repair has been successfully performed both laparoscopically and thoracoscopically in infants and children. ${ }^{1-3}$ However, our initial report of neonatal thoracoscopic $\mathrm{CDH}$ repair suggested the need for refinement in techniques and better patient selection criteria. ${ }^{4}$ Since then, further reports have proven that it is feasible, safe, and effective. ${ }^{5-14,19}$

Although prenatal diagnosis of $\mathrm{CDH}$ tends to be a worse prognostic factor, a favorable LHR without liver herniation may actually predict a good prognosis and may be associated with successful thoracoscopic repair. Two of the 6 patients who were prenatally diagnosed required open repair with a patch-one was diagnosed at another hospital and the other had an LHR of 1.2 at 32 weeks EGA, which predicted a less favorable prognosis. Among the other patients, a favorable LHR correlated with successful repair by thoracoscopic approach and corresponded with their minimal ventilator settings. The high predicted survival of $83 \%$ by the CDHSG equation further suggests that patients in our population were less severe and more likely to undergo successful repair by a thoracoscopic approach. Repair was generally performed within the first week of life, suggesting that the ability to adequately stabilize these patients in this time period favorably disposes them to successful thoracoscopic repair. The 1 patient who was repaired on DOL 23 and had required ECMO and HFOV for stabilization prior to repair was found to have a large diaphragmatic defect intraoperatively requiring patch closure. In keeping with findings by Lally and the CDHSG, the large hernia defect in this patient may be thought of as a surrogate marker for pulmonary hypoplasia, predictive of a worse prognosis overall and an indicator of the need for open repair. $^{20}$

Three patients of $15(20 \%)$ received repairs with conversion to open. One patient experienced dangerously high intraoperative PIP levels, raising a concern for barotrauma, leading to the decision to open. The other 2 patients required patch closure, 1 due to the inability to adequately place the patch thoracoscopically and another due to the large size of the diaphragmatic defect. Conversion rates in the recent literature range from 3.4 to $14 \%,{ }^{5,9,13}$ with 2 cases ${ }^{6,12}$ reporting no conversions of up to 15 patients. Our conversion rate is comparatively high, but this should be interpreted in the context of pushing the boundaries of MIS repair in higher risk patients, such as those requiring ECMO.

A comparison of completely thoracoscopic repairs to those with conversion to open has not been previously reported. In our study population, the patients who underwent a thoracoscopic repair with conversion to open spent a longer time in the operating room. Our average operating time of 161 minutes is generally comparable to the literature, with most reported thoracoscopic $\mathrm{CDH}$ repair times in neonates falling in a range between 112 and 180 minutes. ${ }^{4,6,13,19}$ However, a recent study by $\mathrm{Cho}$ et al. compared 29 thoracoscopic repairs to 28 open repairs, finding that operative times for thoracoscopic repair (180 minutes) were significantly longer than those for open procedures (117 minutes). ${ }^{13}$ As would be expected, our data showed that repairs took longer when converted to open procedures (155 minutes for T, 195 for TO). These patients spent a significantly longer time on the ventilator postoperatively and in general. In addition, these patients took a longer time to tolerate full enteral feeding and had a significantly longer LOS. Cho et al.'s study showed that total and postoperative ventilator times and time to feeding were similar whether patients underwent thoracoscopic or open repair. In comparison, we saw that patients in the TO group appeared to do worse overall, compared to the T group. Although this is likely due to the increased severity of the $\mathrm{CDH}$ defects in this group, as suggested by factors such as less favorable LHR calculation, history of long-term ECMO use, and high-intraoperative PIP, strict interpretation of these data are limited by the small number of patients in the TO group.

There is a wide range of reported complications associated with thoracoscopic $\mathrm{CDH}$ repair. Postoperative complication rates ranged from 11 to $55 \%,{ }^{4,9,13}$ Cho et al. reported a very inclusive list of complications potentially related to thoracoscopy and had the highest complication rate reported (55\%). ${ }^{13}$ Excluding conversion to open repair, our overall complication rate was $27 \%$. We had only one complication, a postoperative pneumothorax requiring chest-tube placement, in the T group.

Because follow-up is often short term, reported recurrence rates may not be accurate in the literature. Nevertheless, these rates range from 14 to $21 \%$, similar to our rate of $17 \%$. ${ }^{6,12,13}$ Of note, our recurrences both occurred in the T group.

Efforts have been made to predict which patients will require conversion to open repair. ${ }^{12,21}$ A study by Yang et al. employed predetermined criteria to select patients for thoracoscopic repair, such as a lack of stomach herniation by radiograph and use of minimal ventilator settings (PIP $<24 \mathrm{~mm}$ 
$\mathrm{Hg}$, PEEP of 5, RR of $50-70 \mathrm{bpm}$, and tidal volumes of $4-5 \mathrm{~mL} / \mathrm{kg}){ }^{12}$ Three of the 5 patients in our study with stomach herniation did require open repair, 2 with a patch. The ventilator settings for these patients, like those for our patients overall, fell within Yang et al.'s criteria for minimal settings. Thus, though the presence of stomach herniation was clearly associated with the need for conversion to open, it did not universally mandate open repair.

Until recently, patch repair has been thought to necessitate conversion to open repair, but there have been several reports of successful thoracoscopic patch repair. ${ }^{6,13,14}$ Zamakshary et al. sought to develop criteria predictive for the need for patch repair (and, by extension, for the failure of thoracoscopic repair) and determined these to be prenatal diagnosis, elements of the immediate postnatal $\mathrm{ABG}\left(\mathrm{pCO}_{2}>34 \mathrm{~mm} \mathrm{Hg}\right.$ or $\mathrm{SaO}_{2}<93 \%$ ), EGA, Apgar score at 5 minutes, and use of modalities other than conventional mechanical ventilation [specifically, HFOV, surfactant, inhaled nitric oxide (iNO), and paralysis]. ${ }^{21}$ In our group, 6 patients were diagnosed prenatally, but only 2 required open repair with the use of a patch. Although 6 patients had a high immediate postnatal $\mathrm{pCO}_{2}$, only 2 required conversion to open, with 1 receiving a patch repair. The single patient who required both HFOV and ECMO did receive a patch repair requiring a conversion to open. Taken together, our data partially corroborate Zamakshary et al.'s proposed predictive criteria as at least indicative of patients with severe $\mathrm{CDH}$ defects and possible need for open repair.

Surprisingly, the use of alternate modalities to conventional ventilation did not necessarily correlate with the need for open or patch repair. Indeed, though 3 patients had severe enough initial respiratory distress that they received a surfactant, HFOV, and/or ECMO, only 1 of these required open repair with a patch after having received both HFOV and ECMO. Cho et al. showed that of 29 successful thoracoscopic CDH repairs, 2 patients had received ECMO prior to their repair. ${ }^{13}$ Thus, there appears to be no absolute contraindication to attempting thoracoscopic repair, and these criteria ought to be interpreted within the context of the individual patient.

\section{Conclusions}

Thoracoscopic CDH repair is a safe, effective operative approach in neonates who have been stabilized. This MIS approach appears most successful in the less severe subset of $\mathrm{CDH}$ patients, as corroborated by favorable LHR, lack of stomach herniation, adequate support by conventional ventilation alone, and the ability to repair the defect primarily within the first week of life. With technical advances and increased surgical experience, however, the thoracoscopic approach may well have broader application in higher risk patients if they can be adequately stabilized prior to repair.

\section{Disclosure Statement}

No competing financial interests exist.

\section{References}

1. Becmeur F, Jamali RR, Moog R, Keller L, Christmann D, Donato L, Kauffmann I, Schwaab C, Carrenard G, Sauvage
P. Thoracoscopic treatment for delayed presentation of congenital diaphragmatic hernia in the infant. A report of three cases. Surg Endosc 2001;15:1163-1166.

2. Kohno M, Ikawa H, Okamoto S, Fukumoto H, Masuyama H, Konuma K, Kohno M, Ikawa H, Okamoto S, Fukumoto H, Masuyama H, Konuma K. Laparoscopic repair of latepresenting Bochdalek hernia in 2 infants. Surg Laparosc Endosc Percutan Tech 2007;17:317-321.

3. Szavay PO, Drews K, Fuchs J, Szavay PO, Drews K, Fuchs J. Thoracoscopic repair of a right-sided congenital diaphragmatic hernia. Surg Laparosc Endosc Percutan Tech 2005; 15:305-307.

4. Arca MJ, Barnhart DC, Lelli JL, Jr, Greenfeld J, Harmon CM, Hirschl RB, Teitelbaum DH. Early experience with minimally invasive repair of congenital diaphragmatic hernias: Results and lessons learned. J Pediatr Surg 2003;38:1563-1568.

5. Becmeur F, Reinberg O, Dimitriu C, Moog R, Philippe P. Thoracoscopic repair of congenital diaphragmatic hernia in children. Semin Pediatr Surg 2007;16:238-244.

6. Guner YS, Chokshi N, Aranda A, Ochoa C, Qureshi FG, Nguyen NX, Grikscheit T, Ford HR, Stein JE, Shin CE. Thoracoscopic repair of neonatal diaphragmatic hernia. J Laparoendosc Adv Surg Tech A 2008;18:875-880.

7. Liem NT, Dung LA, Nhat LQ, Ung NQ. Thoracoscopic repair for right congenital diaphragmatic hernia. I Laparoendosc Adv Surg Tech A 2008;18:661-663.

8. Liem NT, Liem NT. Thoracoscopic surgery for congenital diaphragmatic hernia: A report of nine cases. Asian J Surg 2003;26:210-212.

9. Nguyen TL, Le AD, Nguyen TL, Le AD. Thoracoscopic repair for congenital diaphragmatic hernia: Lessons from 45 cases. J Pediatr Surg 2006;41:1713-1715.

10. Schaarschmidt K, Strauss J, Kolberg-Schwerdt A, Lempe M, Schlesinger F, Jaeschke U. Thoracoscopic repair of congenital diaphragmatic hernia by inflation-assisted bowel reduction, in a resuscitated neonate: A better access? Pediatr Surg Int 2005;21:806-808.

11. Shalaby R, Gabr K, Al-Saied G, Ibrahem M, Shams A-M, Dorgham A, Ismail M. Thoracoscopic repair of diaphragmatic hernia in neonates and children: A new simplified technique. Pediatr Surg Int 2008;24:543-547.

12. Yang EY, Allmendinger N, Johnson SM, Chen C, Wilson JM, Fishman SJ. Neonatal thoracoscopic repair of congenital diaphragmatic hernia: Selection criteria for successful outcome. J Pediatr Surg 2005;40:1369-1375.

13. Cho SD, Krishnaswami S, McKee JC, Zallen G, Silen ML, Bliss DW. Analysis of 29 consecutive thoracoscopic repairs of congenital diaphragmatic hernia in neonates compared to historical controls. I Pediatr Surg 2009;44:80-86; discussion, 86.

14. Shah SR, Gittes GK, Barsness KA, Kane TD. Multimedia article. Thoracoscopic patch repair of a right-sided congenital diaphragmatic hernia in a neonate. Surg Endosc 2009;23:215.

15. Metkus AP, Filly RA, Stringer MD, Harrison MR, Adzick NS. Sonographic predictors of survival in fetal diaphragmatic hernia. J Pediatr Surg 1996;31:148-151; discussion, 151-152.

16. Boloker J, Bateman DA, Wung JT, Stolar CJ. Congenital diaphragmatic hernia in 120 infants treated consecutively with permissive hypercapnea/spontaneous respiration/elective repair. J Pediatr Surg 2002;37:357-366.

17. Kays DW, Langham MR, Jr, Ledbetter DJ, Talbert JL. Detrimental effects of standard medical therapy in congenital diaphragmatic hernia. Ann Surg 1999;230:340-348; discussion 348-351. 
18. The Congenital Diaphragmatic Hernia Study Group. Estimating disease severity of congenital diaphragmatic hernia in the first 5 minutes of life. J Pediatr Surg 2001;36:141-145.

19. Shah SR, Wishnew J, Barsness K, Gaines BA, Potoka DA, Gittes GK, Kane TD. Minimally invasive congenital diaphragmatic hernia repair: A 7-year review of one institution's experience. Surg Endosc 2008, Oct 2. [Epub ahead of print]

20. Lally KP, Lally PA, Lasky RE, Tibboel D, Jaksic T, Wilson JM, Frenckner B, Van Meurs KP, Bohn DJ, Davis CF, Hirschl RB. Defect size determines survival in infants with congenital diaphragmatic hernia. Pediatrics 2007;120:e651-e657.

21. Zamakhshary M, Mah K, Mah D, Cameron B, Bohn D, Bass J, Scott L, Kim PCW. Physiologic predictors for the need for patch closure in neonatal congenital diaphragmatic hernia. Pediatr Surg Int 2008;24:667-670.

Address correspondence to: George B. Mychaliska, MD Section of Pediatric Surgery University of Michigan Hospitals Mott Children's Hospital F3970

P.O. Box 0245

Ann Arbor, MI 48109

E-mail: mychalis@med.umich.edu 
This article has been cited by:

1. Tadaharu Okazaki, Kinya Nishimura, Toshiaki Takahashi, Hiromichi Shoji, Toshiaki Shimizu, Toshitaka Tanaka, Satoru Takeda, Eiichi Inada, Geoffrey J. Lane, Atsuyuki Yamataka. 2010. Indications for thoracoscopic repair of congenital diaphragmatic hernia in neonates. Pediatric Surgery International . [CrossRef]

2. Nick Lansdale, Sabrina Alam, Paul D. Losty, Edwin C. Jesudason. 2010. Neonatal Endosurgical Congenital Diaphragmatic Hernia Repair. Annals of Surgery 252:1, 20-26. [CrossRef] 